\title{
Gypenosides attenuate cholesterol-induced DNA damage by inhibiting the production of reactive oxygen species in human umbilical vein endothelial cells
}

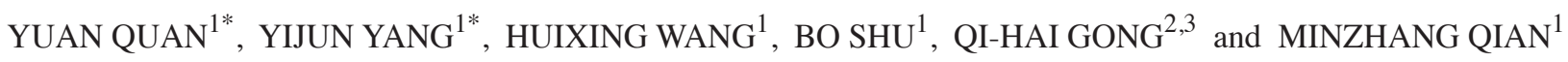 \\ Departments of ${ }^{1}$ Biochemistry and ${ }^{2}$ Pharmacology; ${ }^{3}$ The Key Laboratory of Basic Pharmacology of Guizhou Province, \\ Zunyi Medical College, Zunyi, Guizhou 563000, P.R. China
}

Received December 3, 2013; Accepted September 12, 2014

DOI: $10.3892 / \mathrm{mmr} .2014 .3095$

\begin{abstract}
Previous studies have demonstrated that DNA damage induces atherosclerosis and that oxidative stress has an important role in DNA damage. Gypenosides (Gps), the main ingredient of Gynostemma Pentaphylla (Thunb.) Makino, have been recognized as specific antioxidants and have previously been reported to inhibit high-fat diet-induced atherosclerosis in rats. However, whether or not Gps attenuate DNA damage through their antioxidant effects remains to be elucidated. The current study was performed to clarify whether or not Gps can inhibit cholesterol-induced DNA damage through antioxidation. The present study provided new insights into the pharmacological effects of Gps on atherosclerosis. HUVECs were treated with $G p s$ at various concentrations $(1,10$ and $100 \mu \mathrm{g} / \mathrm{ml})$ for $1 \mathrm{~h}$. The protective effects of Gps on cholesterol-induced DNA damage were determined using immunofluorescence, western blotting, reverse-transcription quantitative polymerase chain reaction and flow cytometry. Pretreatment with Gps (1, 10 and $100 \mu \mathrm{g} / \mathrm{ml})$ effectively attenuated cholesterol-induced DNA damage in HUVECs by inhibiting phosphorylation of H2AX, a member of the histone family. Furthermore, Gps $(100 \mu \mathrm{g} / \mathrm{ml})$ pretreatment inhibited cholesterol-induced transcription and activity of nicotinamide adenine dinucleotide phosphate-oxidase 4 and
\end{abstract}

Correspondence to: Professor Minzhang Qian, Department of Biochemistry, Zunyi Medical College, 201 Dalian Road, Zunyi, Guizhou 563000, P.R. China

E-mail: qian_mzh@hotmail.com

*Contributed equally

Abbreviations: HUVECs, human umbilical vein endothelial cells; ROS, reactive oxygen species; NOS, nitric oxide synthase; XOD, xanthine oxidase; NOX, nicotinamide adenine dinucleotide phosphate oxidase; $\gamma \mathrm{H} 2 \mathrm{AX}$, phosphorylation of histone $\mathrm{H} 2 \mathrm{AX} ; \mathrm{CH}$, cholesterol; Gps, gypenosides; FBS, fetal bovine serum

Key words: Gynostemma Pentaphylla (Thunb.) Makino, Gypenosides, oxidative stress, DNA damage, atherosclerosis reduced intracellular ROS levels. In conclusion, Gps attenuated cholesterol-induced DNA damage by inhibiting ROS production in HUVECs, suggesting that the inhibitory effect of Gps on atherogenesis is correlated with the alleviation of DNA damage.

\section{Introduction}

Gynostemma pentaphylla (Thunb.) Makino. is a cucurbitaceous herbaceous vine used widely in China containing saponins, amino acids, flavonoids and numerous inorganic elements (1). Gypenosides (Gps), the main ingredient of Gynostemma Pentaphylla (Thunb.) Makino, are rich in dammarane-type monomer saponins (2). Gps are known to possess a number of pharmacological properties, including anti-aging, cardioprotective and neuroprotective effects. Our previous study demonstrated that Gps enhanced superoxidase (SOD) activity in serum and tissues, decreased serum malondialdehyde and levels of oxidized low-density lipoprotein as well as increased total antioxidant ability (3). In addition, Gps inhibited nuclear factor- $\kappa \mathrm{B}$ activation and inflammatory factor expression and also attenuated the pathological alterations of high-fat diet-induced atherosclerosis in rats (3). Taken together, Gps-mediated antioxidant effects warrant further investigation.

DNA damage has been reported to correlate with atherosclerotic disease (4). DNA damage occurs in genomic and mitochondrial DNA in the circulating cells of patients with atherosclerosis, and their plaques $(5,6)$. Furthermore, DNA damage can induce cell proliferation, apoptosis and mitochondrial dysfunction as well as promote atherosclerosis by inducing ketosis and hyperlipidemia by increasing fat storage. Reactive oxygen species (ROS) are considered to be important factors leading to DNA damage (4). Our previous studies indicated that cholesterol induced phosphorylation of histone $\mathrm{H} 2 \mathrm{AX}(\gamma \mathrm{H} 2 \mathrm{AX})$ and then increased the levels of $\gamma \mathrm{H} 2 \mathrm{AX}$ and intracellular ROS in human umbilical vein endothelial cells (HUVECs) $(7,8)$. These results suggested that ROS are important in cholesterol-induced DNA damage in HUVECs.

\section{Materials and methods}

Plant material and chemicals. Dry powder of Gps were purchased from Xi'an SoBeo PharmTech Co., Ltd. (Xi'an, 
China; cat no. WS3-Z-006-93Z). Ginsenoside standard substances were purchased from the National Institutes for Food and Drug Control (Beijing, China). Cholesterol was purchased from Sigma (St. Louis, MO, USA). Mouse anti- $\gamma \mathrm{H} 2 \mathrm{AX}$ monoclonal antibody was purchased from Upstate Biotechnology, Inc. (Lake Placid, NY, USA). Rabbit anti-human NOX4 monoclonal antibody was purchased from Santa Cruz Biotechnology, Inc. (Santa Cruz, CA, USA). Goat anti-mouse fluorescein isothiocyanate-conjugated antibodies and mouse anti-human monoclonal antibody, Triton X-100, blocking buffer (goat serum) and 4', 6'-diamidino-2-phenylindole were purchased from Beyotime Institute of Biotechnology (Haimen, China). TRIzol was purchased from Invitrogen Life Technologies (Carlsbad, CA, USA). SDS-PAGE was purchased from Sangon Biological Engineering Co., Ltd. (Shanghai, China). Light-Cycler-DNA Master SYBR Green I mix was purchased from Roche Applied Science (Indianapolis, IN, USA).

High performance liquid chromatography (HPLC) analysis. Gps and Ginsenoside standard substances $\left(\mathrm{Rb}_{1}\right.$ and $\left.\mathrm{Rb}_{2}\right)$ were dissolved in methanol. The solution was filtered through a $0.45 \mu \mathrm{m}$ syringe prior to HPLC analysis. HPLC analysis for the powder of Gps was performed on a SB-C18 column (4.6x150 $\mu \mathrm{m}, 5 \mu \mathrm{m}$; Agilent Technologies, Santa Clara, CA, USA) in Agilent 1100 (9). The mobile phase consisted of water and acetonitrile, with a gradient elution of 5-100\% acetonitrile between 0 and $60 \mathrm{~min}$, the column temperature was maintained at $30^{\circ} \mathrm{C}$. The flow rate was $1.0 \mathrm{ml} / \mathrm{min}$ and the wavelength was $203 \mathrm{~nm}$. The sample injection volume was $20 \mu \mathrm{l}$.

Cell culture. HUVECs were obtained from the American Type Culture Collection (Manassas, VA, USA). The cell lines were maintained in RPMI-1640 or F12 medium supplemented with penicillin $(80 \mathrm{U} / \mathrm{ml})$, streptomycin $(100 \mathrm{U} / \mathrm{ml})$ and $10 \%$ fetal bovine serum at $37^{\circ} \mathrm{C}$ in a humid environment containing $5 \% \mathrm{CO}_{2}$.

Drug treatment. HUVECs were seeded into a 6-well plate at a density of $2 \times 10^{5}$ cells $/ \mathrm{ml}$. The cells were pretreated with $G p s$ $(1,10$ and $100 \mu \mathrm{g} / \mathrm{ml})$ for $1 \mathrm{~h}$ followed by cholesterol $(50 \mathrm{mg} / \mathrm{l})$ treatment for $12 \mathrm{~h}$.

Immunofluorescence. Cells were seeded on glass slides and then the slides were washed with phosphate-buffered saline followed by fixing in $4 \%$ paraformaldehyde at $4^{\circ} \mathrm{C}$ for $10 \mathrm{~min}$. The cell membrane was lysed with Triton X-100 and then placed in blocking buffer with $100 \mu \mathrm{l}$ goat serum for $2 \mathrm{~h}$. The samples were incubated with mouse anti- $\gamma \mathrm{H} 2 \mathrm{AX}$ monoclonal antibody for $2 \mathrm{~h}$ and goat anti-mouse FITC-conjugated secondary antibody for $1 \mathrm{~h}$. The nuclei were stained with 4',6-diamidino-2-phenylindole and visualized using fluorescence microscopy (Olympus IX17; Olympus Corporation, Tokyo, Japan). Images were captured at x400 magnification.

Cell lysate preparation and immunoblotting. Cells were lysed in lysis buffer (Wuhan Boster Bioengineering Ltd., Wuhan, China) and the protein content in the supernatant was determined using the bicinchoninic acid method. Proteins $(20 \mu \mathrm{g})$ were electrophoresed on $10 \%$ SDS-PAGE followed by transfer onto a polyvinylidene difluoride membrane (Millipore, Billerica, MA, USA). Following being blocked with 5\% skimmed milk in Tris-buffered saline containing $0.1 \%$ Tween-20 (TBST), the membranes were incubated with the primary antibodies (mouse anti- $\gamma \mathrm{H} 2 \mathrm{AX}$ and rabbit anti-human NOX4 monoclonal antibodies; $1: 1000$ ) at $4{ }^{\circ} \mathrm{C}$ overnight. The membranes were washed with TBST and incubated with horseradish peroxidase-conjugated secondary antibodies. The immunoreactive bands were detected by enhanced chemiluminescent reagents (Sigma). To account for the potential variations in protein estimation and sample loading, the expression of each protein was compared with that of $\beta$-actin in each sample following stripping the blot.

Flow cytometric analysis. To detect ROS production, cells were collected and suspended with dichloro-dihydro-fluorescein diacetate (DCFH-DA; $10 \mu \mathrm{M})$ solubilized in ethanol. Subsequently, cells were incubated at $37^{\circ} \mathrm{C}$ in the dark for $30 \mathrm{~min}$. Following incubation, cells were subjected to flow cytometry. DCFH-DA is a nonpolar dye, which is converted into the polar derivative DCFH by cellular esterase. DCFH is nonfluorescent but switches to high fluorescence DCF following oxidization by intracellular ROS. DCF has an excitation wavelength of $488 \mathrm{~nm}$ and an emission band of $530 \mathrm{~nm}$. The results were analyzed using CellQuest software and ROS levels were assessed by measuring the intensity of DCF.

Nitric oxide synthase (NOS) activity assay. Cells were pretreated with Gps $(100 \mu \mathrm{g} / \mathrm{ml})$ for $1 \mathrm{~h}$ and then treated with cholesterol $(50 \mathrm{mg} / \mathrm{l})$ for $48 \mathrm{~h}$. NOS activity in the culture medium was detected using a spectrophotometric method. The absorbance of the mixture was measured at $530 \mathrm{~nm}$ and the total activity of NOS was calculated using the following equation:

Total NOS activity $(\mathrm{U} / \mathrm{ml})=\left[\left(\mathrm{OD}_{\text {test }}-\mathrm{OD}_{\text {control }}\right) /(38\right.$. $\left.3 \times 10^{-6}\right) \times[$ (total volume of reaction solution) $/($ mass of sample) $\mathrm{x}[1 /(1 \mathrm{x} 15) / 1000]$

Xanthine oxidase (XOD) activity. XOD can oxidize hypoxanthine to xanthine and also produce the superoxide anion radical, which can react with a chromogenic reagent to generate a purple/red product. The color was measured using a spectrophotometer (Bio-Rad Laboratories, Hercules, CA, USA) at $570 \mathrm{~nm}$ and the XOD activity was quantified by measuring color intensity. The following equation was used to calculate the activity of XOD:

XOD activity $(\mathrm{U} / \mathrm{L})=\left[\left(\mathrm{OD}_{\text {test }}-\mathrm{OD}_{\text {control }}\right) /(12.6 \mathrm{x} 10)\right] \mathrm{x}$ attenuation times $\mathrm{x}[1 /(1 \mathrm{x} 20)]$

Intracellular NOX quantification. HUVECs were placed into the tissue culture flask $\left(25 \mathrm{~cm}^{2}\right)$ at a density of $5 \times 10^{5}$ cells $/ 1$. Subsequently, cells were treated with cholesterol for $48 \mathrm{~h}$ and NOX activity was determined using a specific kit (Nanjing Jiancheng Bioengineering Institute, Nanjing, China). The absorbance of the mixture was measured at $550 \mathrm{~nm}$ and the total activity of NOX was calculated. The total activity of NOX was calculated using the following equation: 
Total activity of sample $=\left[\left(\mathrm{S}_{\text {sample }}-\mathrm{S}_{\text {background }}\right) \times\right.$ sample attenuation times)]/[0.01 $\mathrm{mg}$ (mass of sample) $\mathrm{x} 21.2$ (absorbance) $\mathrm{x} 15 \mathrm{~min}$ ]

Reverse-transcription quantitative polymerase chain reaction $(R T-q P C R)$. Total RNA was isolated using TRIzol reagent (Invitrogen Life Technologies) according to the manufacturer's instructions and reverse transcribed. Briefly, the cDNA was amplified in a $20 \mu 1$ reaction containing primer pairs (each $0.25 \mu 1$ ): $\beta$-actin, forward 5'-GTGGGGCGCCCCAGGCACCA-3' and reverse 5'-CTCCTTAATGTCACGCACGATTTC-3' and NOX4, forward 5'-AGATGTTGGGGCTAGGATTG-3' and reverse 5'-TCTCCTGCTTGGAACCTTCT-3', 10X buffer $(5.0 \mu \mathrm{l})$, cDNA $(2.0 \mu \mathrm{l}), 25 \mathrm{mmol} / 1 \mathrm{MgCl}_{2}(4.0 \mu \mathrm{l}), 10 \mathrm{mmol} / 1 \mathrm{dNTPs}$ $(1.0 \mu \mathrm{l})$ and Taq polymerase $(1.25 \mu \mathrm{l})$. PCR amplification cycles consisted of denaturation at $94^{\circ} \mathrm{C}$ for $1 \mathrm{~min}$, primer annealing at $58^{\circ} \mathrm{C}$ for $30 \mathrm{sec}$ and extension at $72^{\circ} \mathrm{C}$ for $30 \mathrm{sec}$ for a total of 30 cycles followed by final extension at $72^{\circ} \mathrm{C}$ for $7 \mathrm{~min}$. The PCR product was separated by electrophoresis on a $5 \%$ agarose gel.

Statistical analysis. Data are expressed as the mean \pm standard deviation. Statistical significance of differences between groups were assessed using Student's t-test. All calculations were performed using SPSS 16.0 software (SPSS, Inc., Chicago, IL, USA). $\mathrm{P}<0.05$ was considered to indicate a statistically significant difference.

\section{Results}

HPLC fingerprint of Gps. The Gps powder was analyzed by HPLC. The results revealed distinct characteristic peaks (Fig. 1). Compared with ginsenoside standard substances $\left(\mathrm{Rb}_{1}\right.$ and $\mathrm{Rb}_{2}$, Fig. $2 \mathrm{~A}$ and $\mathrm{B}$ ), Peak 1 and 2 were similar to ginsenoside $\mathrm{Rb}_{1}$ and $\mathrm{Rb}_{2}$ in structure and chemical character, respectively.

Gps decreases the intensity of $\gamma H 2 A X$ foci formation. The effects of Gps on cholesterol-induced $\gamma \mathrm{H} 2 \mathrm{AX}$ foci formation was investigated using an immunofluorescence assay. Compared with the negative control group (Fig. 3A), cholesterol significantly increased the intensity of $\gamma \mathrm{H} 2 \mathrm{AX}$ foci formation (Fig. 3B). However, Gps pretreatment decreased the intensity of $\gamma \mathrm{H} 2 \mathrm{AX}$ foci formation (Fig. 3C-E). Furthermore, compared with the control group (Fig. 4), the intensity of $\gamma \mathrm{H} 2 \mathrm{AX}$ foci formation was markedly decreased by Gps. Gps consistently decreased the cholesterol-induced increase in $\gamma \mathrm{H} 2 \mathrm{AX}$ expression as identified by western blot assay (Fig. 5).

Gps decreases ROS in HUVECs. To detect ROS levels in HUVECs, ROS production was measured by flow cytometry. Compared with the control group, cholesterol significantly increased ROS production and this increase was attenuated by $G p s$ (Fig. 6A). Together, Gps inhibited cholesterol-induced ROS production in HUVECs (Fig. 6B).

Effects of Gps on the activity of NOX, XOD and NOS in cholesterol-treated HUVECs. The effects of Gps on NOX,

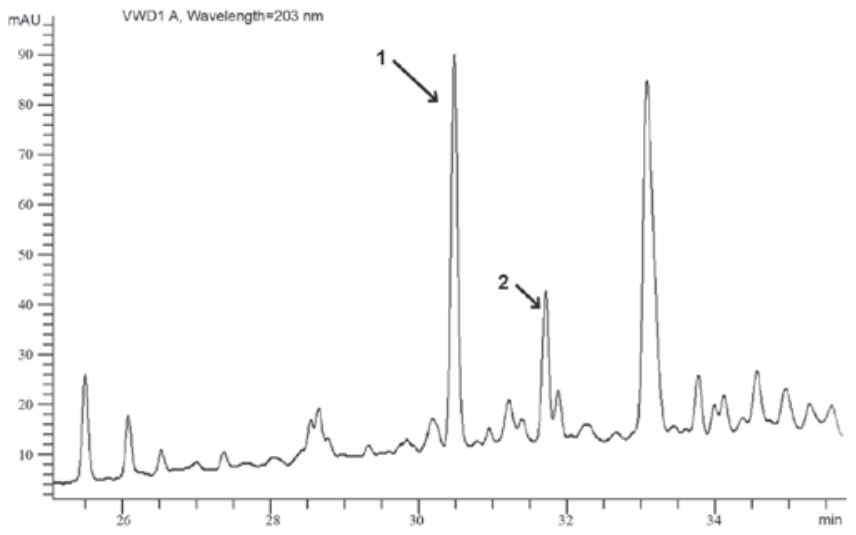

Figure 1. High performance liquid chromatography fingerprint profile of gypenosides. The first peak (arrow 1) and the second peak (arrow 2) presented a substance which had a similar structural and chemical character to ginsenoside $\mathrm{Rb}_{1}$ and $\mathrm{Rb}_{2}$, respectively. The mobile phase consisted of water and acetonitrile, with a gradient elution of 5-100\% acetonitrile between 0 and $60 \mathrm{~min}$, the column temperature was maintained at $30^{\circ} \mathrm{C}$ The flow rate was $1.0 \mathrm{ml} / \mathrm{min}$ and the wavelength was $203 \mathrm{~nm}$. The sample injection volume was $20 \mu 1$.

A

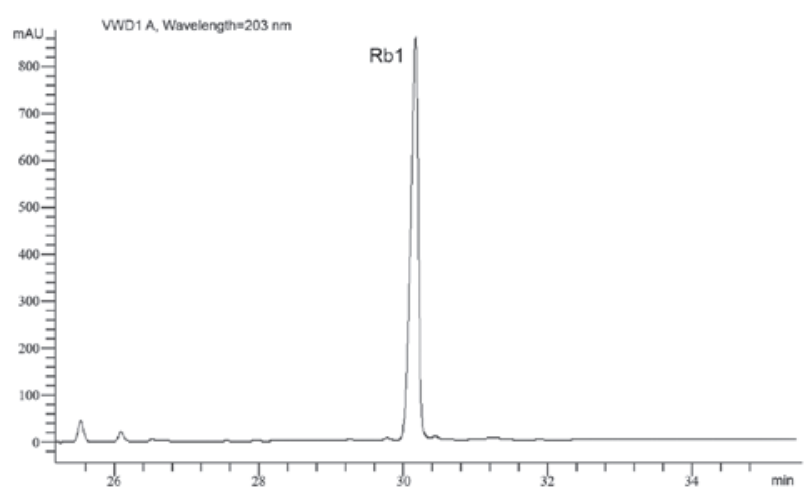

B

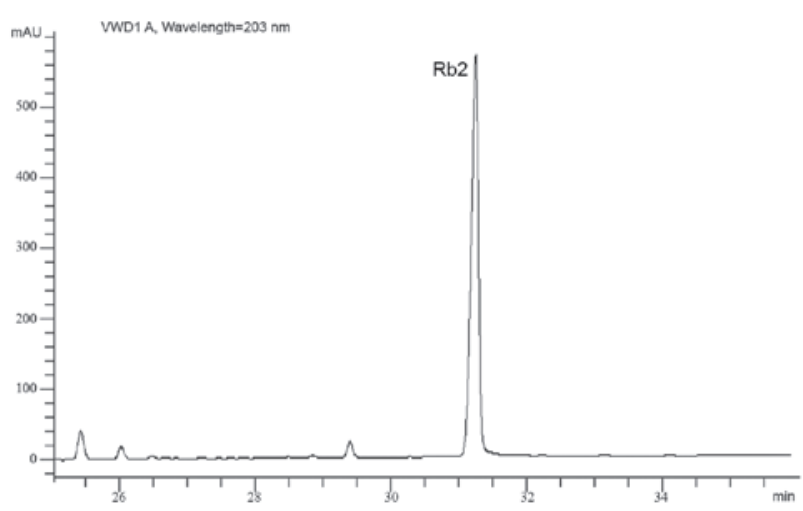

Figure 2. High performance liquid chromatography fingerprint profile of ginsenoside standard substances. The peak A and B presented ginsenoside $\mathrm{Rb}_{1}$ and ginsenoside $\mathrm{Rb}_{2}$, respectively. The mobile phase consisted of water and acetonitrile, with a gradient elution of $5-100 \%$ acetonitrile between 0 and $60 \mathrm{~min}$, the column temperature was maintained at $30^{\circ} \mathrm{C}$. The flow rate was $1.0 \mathrm{ml} / \mathrm{min}$ and the wavelength was $203 \mathrm{~nm}$. The sample injection volume was $20 \mu 1$.

XOD and NOS in HUVECs are listed in Table I. Cholesterol increased the activity of NOX and XOD by 279.45 and $94.33 \mathrm{U} / 1$, respectively, and decreased NOS activity by $374.41 \mathrm{U} / \mathrm{ml}$. Compared with the cholesterol group, Gps 
DAPI

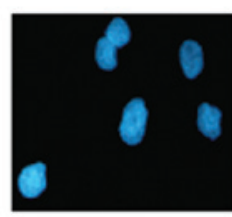

B

C

$\operatorname{Gps}(1 \mu \mathrm{g} / \mathrm{mL})+\mathrm{CH}$

D

\section{$\mathrm{Gps}(10 \mu \mathrm{g} / \mathrm{mL})+\mathrm{CH}$}

\section{E $\operatorname{Gps}(100 \mu \mathrm{g} / \mathrm{mL})+\mathrm{CH}$}
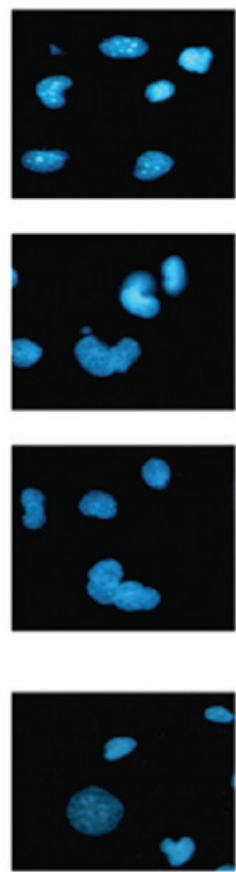

FITC
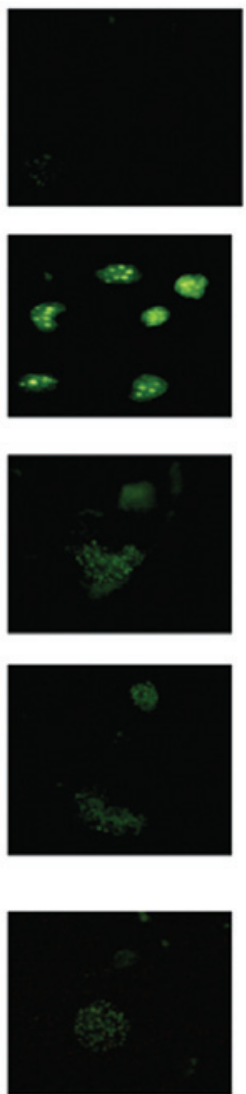

Merge
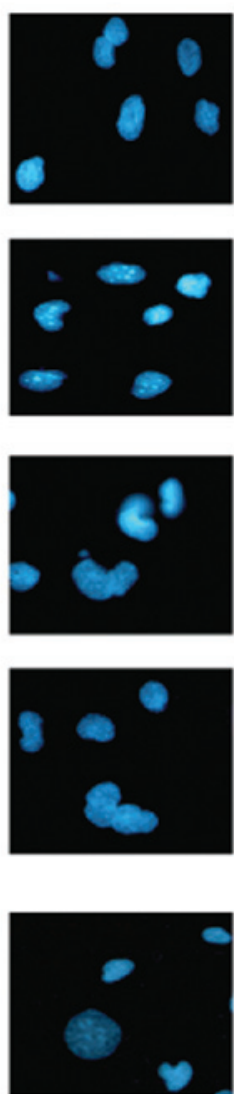

Figure 3. Effects of Gps on $\gamma \mathrm{H} 2 \mathrm{AX}$ foci formation induced by cholesterol. The nuclei were stained with DAPI. $\gamma \mathrm{H} 2 \mathrm{AX}$ was labeled by FITC. Cells were pretreated with $G p s$ for $1 \mathrm{~h}$ followed by $\mathrm{CH}$ treatment for $12 \mathrm{~h}$. Images were captured at x 400 magnification. Compared with the (A) negative control group, cholesterol significantly increased the intensity of (B) $\gamma \mathrm{H} 2 \mathrm{AX}$ foci formation. However, Gps pretreatment decreased the intensity of (C-E) $\gamma \mathrm{H} 2 \mathrm{AX}$ foci formation. Gps, gypenosides; FITC, fluorescein isothiocyanate; DAPI, 4',6-diamidino-2-phenylindole; $\gamma \mathrm{H} 2 \mathrm{AX}$, phosphorylation of histone $\mathrm{H} 2 \mathrm{AX}$; $\mathrm{CH}$, cholesterol.

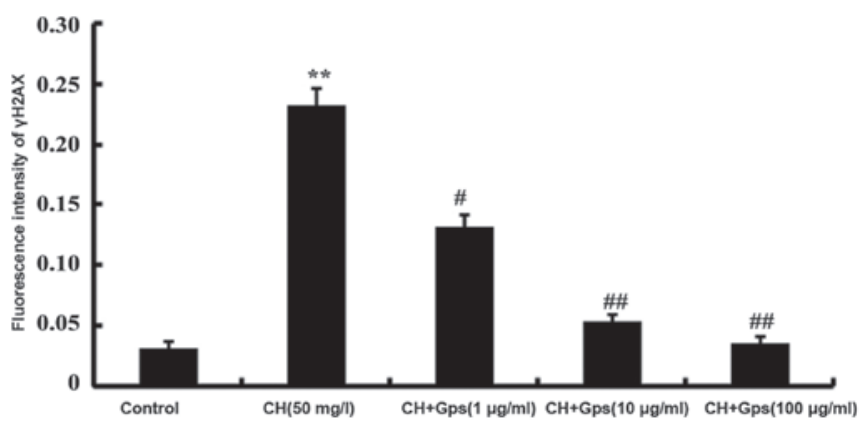

Figure 4. Quantitative results of immunofluorescence. Human umbilical vein endothelial cells were pretreated with $\mathrm{Gps}$ for $1 \mathrm{~h}$ followed by $\mathrm{CH}$ treatment for 12 h. ${ }^{* *} \mathrm{P}<0.05$, compared with the control group; ${ }^{~} \mathrm{P}<0.05$ and ${ }^{\# \#} \mathrm{P}<0.01$ compared with the $\mathrm{CH}$ group. Gps, gypenosides; $\mathrm{CH}$, cholesterol; $\gamma \mathrm{H} 2 \mathrm{AX}$, phosphorylation of histone $\mathrm{H} 2 \mathrm{AX}$.

pretreatment significantly decreased NOX activity and increased NOS activity. However, no significant inhibitory effects of Gps on XOD activity were identified (Table I).

Effects of Gps on NOX4 expression. NOX4 expression was next assessed by RT-qPCR and western blotting. Compared with the cholesterol group, Gps significantly decreased NOX4 mRNA and protein expression (Figs. 7, 8A and B). These
A
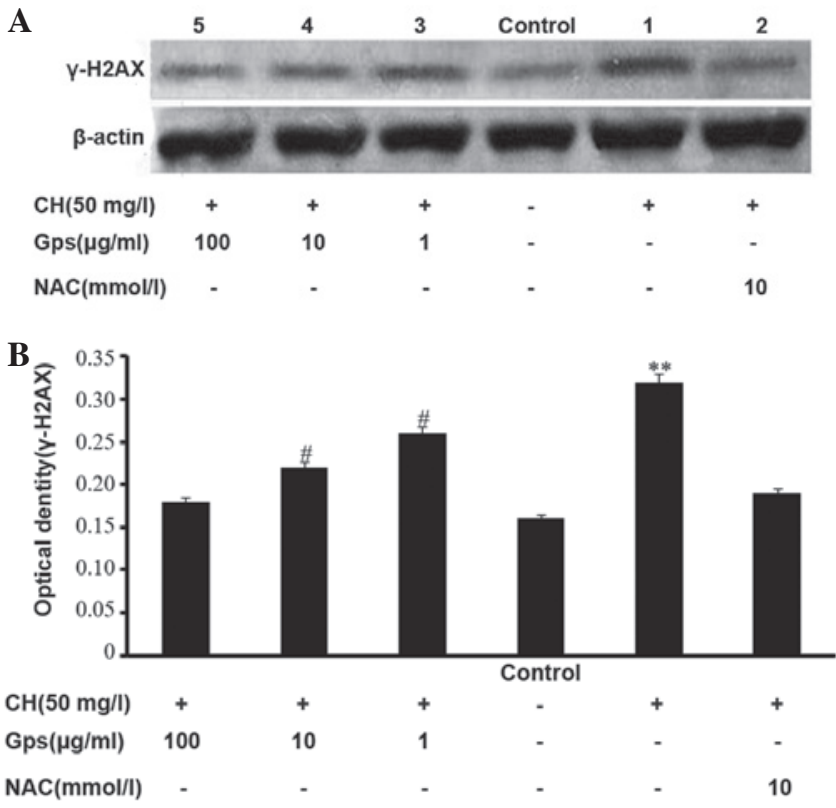

Figure 5. Effects of Gps on the level of $\gamma \mathrm{H} 2 \mathrm{AX}$ expression in human umbilical vein endothelial cells. (A) $\gamma \mathrm{H} 2 \mathrm{AX}$ was determined by immunoblotting with an antibody against $\gamma \mathrm{H} 2 \mathrm{AX}$. (B) Quantitative results of the western blotting assay revealed that Gps decreased $\mathrm{CH}$-induced $\gamma \mathrm{H} 2 \mathrm{AX}$ foci formation. ${ }^{* *} \mathrm{P}<0.01$, compared with the control group; ${ }^{~} \mathrm{P}<0.05$, compared with the $\mathrm{CH}$ group. Gps, gypenosides; $\mathrm{CH}$, cholesterol; NAC, N-acetyl-L-cysteine; $\gamma \mathrm{H} 2 \mathrm{AX}$, phosphorylation of histone H2AX. 
Table I. Effects of Gps on NOX, XOD and NOS activity induced by cholesterol in human umbilical vein endothelial cells.

\begin{tabular}{lllr}
\hline Group & NOX (U/l) & XOD (U/1) & NOS (U/ml) \\
\hline Control & $131.35 \pm 18.64$ & $37.67 \pm 1.50$ & $641.32 \pm 11.92$ \\
Cholesterol & $279.45 \pm 35.12^{\mathrm{a}}$ & $94.33 \pm 13.90^{\mathrm{a}}$ & $374.41 \pm 15.38^{\mathrm{a}}$ \\
Gps $(100 \mu \mathrm{g} / \mathrm{ml})$ & $170.02 \pm 15.60^{\mathrm{b}}$ & $91.17 \pm 7.75$ & $487.69 \pm 28.20^{\mathrm{b}}$ \\
\hline
\end{tabular}

${ }^{\mathrm{a}} \mathrm{P}<0.01$, compared with the control group; ${ }^{\mathrm{b}} \mathrm{P}<0.01$, compared with the cholesterol group. Gps, gypenosides; NOX, nicotinamide adenine dinucleotide phosphate oxidase; XOD, xanthine oxidase; NOS, nitric oxide synthase.

A

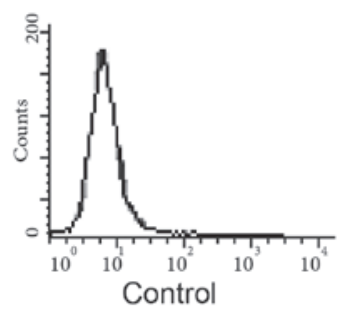

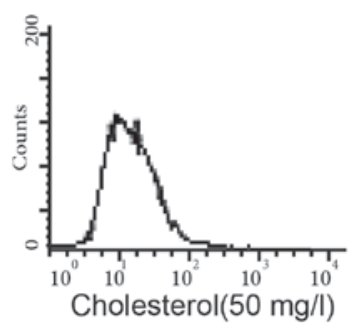

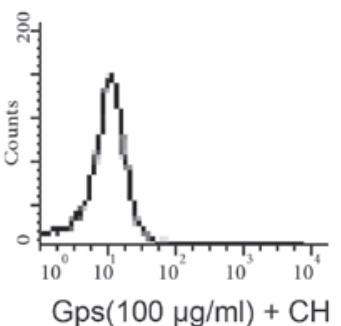

$\mathrm{Gps}(100 \mu \mathrm{g} / \mathrm{ml})+\mathrm{CH}$
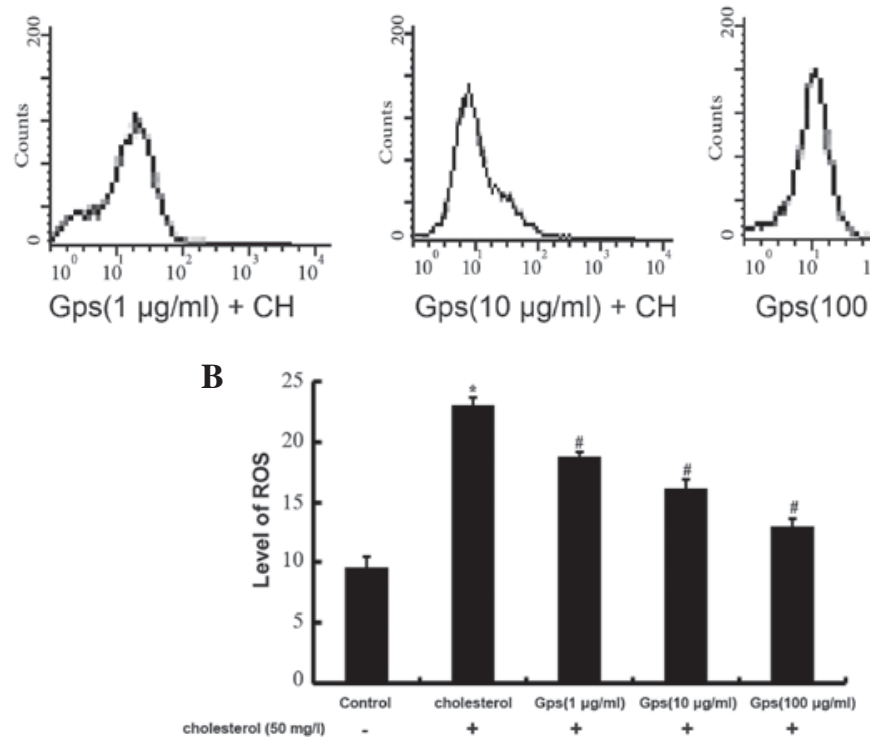

Figure 6. Effects of Gps on ROS production by FACS. (A) ROS production by FACS. (B) Quantitative results of FACS. Cholesterol induced the level of ROS in human umbilical vein endothelial cells. The cells were pretreated with Gps, prior to the addition of cholesterol, the ROS production decreased. "P $<0.05$, compared with the control group; ${ }^{\prime} \mathrm{P}<0.05$, compared with the cholesterol group. Gps, gypenosides; ROS, reactive oxygen species; FACS, fluorescence activated cell sorting.

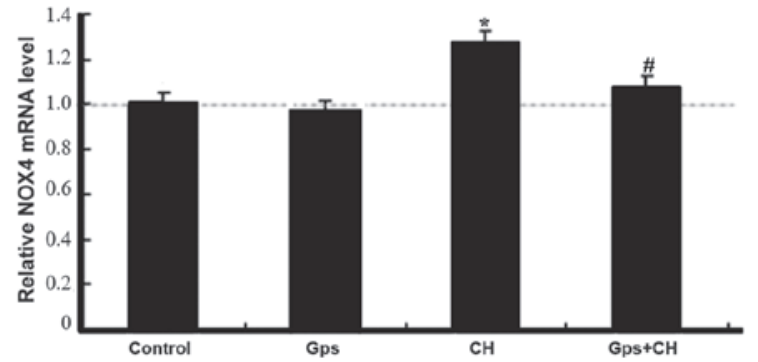

Figure 7. Effects of Gps on the NOX4 mRNA level in human umbilical vein endothelial cells. NOX4 mRNA level was determined by reverse-transcription quantitative polymerase chain reaction. Cells were pretreated with $G p s$ $(100 \mu \mathrm{g} / \mathrm{ml})$ for $1 \mathrm{~h}$ and then, stimulated by $\mathrm{CH}(50 \mathrm{mg} / \mathrm{l})$ for $48 \mathrm{~h} .{ }^{*} \mathrm{P}<0.05$, compared with the control group; ${ }^{*} \mathrm{P}<0.05$, compared with the $\mathrm{CH}$ group. Gps, gypenosides; NOX4, nicotinamide adenine dinucleotide phosphate oxidase $4 ; \mathrm{CH}$, cholesterol. findings suggest that Gps inhibited cholesterol-induced NOX4 expression.

\section{Discussion}

DNA damage may also be called genotoxic stress, and is important in the pathogenesis of atherosclerosis. DNA damage is defined as DNA that has suffered ionizing/X ray radiation, ultraviolet rays, topoisomerase inhibition and oxidative stress, leading to damage. In addition, ROS-induced DNA damage has been considered an essential factor in DNA lesion progress (10). It is well established that histone H2A is phosphorylated rapidly following DNA damage leading to the formation of $\gamma \mathrm{H} 2 \mathrm{AX}$, which is able to assemble other DNA damage repair proteins (11). Therefore, alterations in 
A

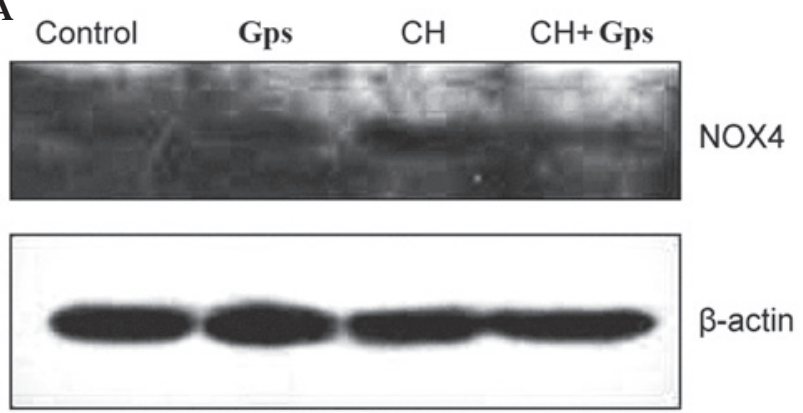

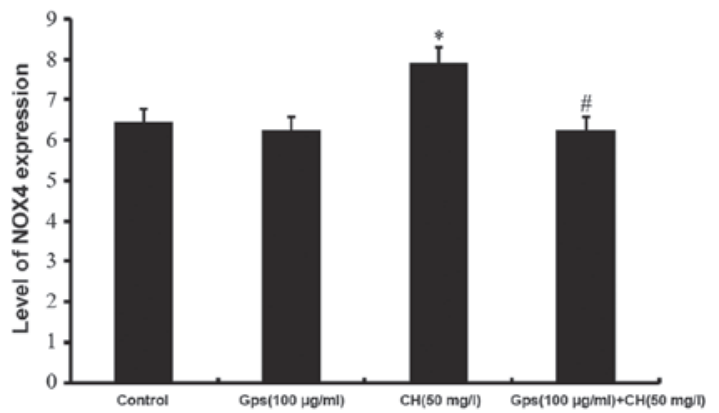

Figure 8. (A and B) Effects of Gps on NOX4 protein level using western blotting. NOX4 protein expression was determined by immunoblotting with an antibody against NOX4. Cells were pretreated with $G p s(100 \mu \mathrm{g} / \mathrm{ml})$ for $1 \mathrm{~h}$ and then stimulated with $\mathrm{CH}(50 \mathrm{mg} / \mathrm{l})$ for $48 \mathrm{~h}$. ${ }^{*} \mathrm{P}<0.05$, compared with the control group; ${ }^{\text {P }}<0.05$, compared with the cholesterol group. Gps, gypenosides; NOX4, nicotinamide adenine dinucleotide phosphate oxidase 4 ; $\mathrm{CH}$, cholesterol.

the levels of $\gamma \mathrm{H} 2 \mathrm{AX}$ and $\gamma \mathrm{H} 2 \mathrm{AX}$ foci formation are recognized as important indicators of DNA damage.

The present study found that cholesterol increased the intensity of $\gamma \mathrm{H} 2 \mathrm{AX}$ foci formation in HUVECs using an immunofluorescence assay. $G p s$ pretreatment significantly reduced the intensity of cholesterol-induced increases in $\gamma \mathrm{H} 2 \mathrm{AX}$ foci formation and decreased ROS production as evidenced by western blotting and flow cytometry. These results demonstrated that Gps can decrease the intracellular ROS levels and attenuate DNA damage.

ROS in vascular endothelial cells are produced by several enzymes, including NOX, XOD, NOS and the respiratory chain complex. Non-phagocytic NAPDH NOX is the main contributor to ROS production in HUVECs $(12,13)$. There are five members of the NOX family, including NOX1, NOX2, NOX3, NOX4 and NOX5. Previous studies demonstrated that the expression of NOX4 in endothelial cells was significantly higher than the expression of other NOX proteins, including gp91phox/Nox2 (14-16). The present study revealed that Gps pretreatment attenuated cholesterol-induced increases in NOX activity and decreases in NOS activity but had no significant effects on XOD activity. These results suggested that cholesterol-increased activity of the main enzymes generating ROS was the main factor inducing ROS production in HUVECs. In addition, Gps inhibited NOX activity and reduced ROS production thereby ameliorating oxidative stress. It was hypothesized that $G p s$-mediated protection in HUVECs was associated in part to enhancing NOS activity and increasing NO production.

$\mathrm{NAD}(\mathrm{P}) \mathrm{H}$ oxidase producing ROS serves as a primary sensor for oxygen. NAD(P)H oxidase was activated and induced overproduction of ROS, which is also considered to have important pathophysiological consequences $(17,18)$. In order to understand the mechanisms underlying Gps-mediated inhibition of NOX activity, an anti-NOX4 antibody was used to detect the expression of NOX4. The present study found that Gps significantly inhibited cholesterol-induced NOX4 expression. To further identify the effects of Gps on NOX4 mRNA expression, it was found that the level of NOX4 mRNA expression was significantly increased following cholesterol treatment and this increase was attenuated by Gps treatment. Thus, Gps may inhibit NOX4 expression at a transcriptional level.

Previous studies indicated that $G p s$ was able to enhance SOD activity and eliminate free radicals $(19,20)$. The present study identified that Gps inhibited NOX4 transcription, decreased NOX4 activity and consequently reduced ROS production, providing new insights into the antioxidant effects of $G p s$.

Under physiological conditions, L-arginine synthesizes a certain amount of NO via NOS catalysis in endothelial cells. $\mathrm{NO}$ is an endothelium-derived relaxing factor, which maintains the vascular function in the endothelium. However, pathological conditions increase NOS activity and NO production leading to the synthesis of the more toxic anion peroxynitrite (ONOO-) (15). Therefore, NOS activity in endothelial cells reflects the function of endothelial cells secreting NO. In the present study, cholesterol decreased the activity of NOS and the subsequent production of NO. By contrast, the decreased capacity of NO synthesis suggested that cell functions were destroyed. Following Gps pretreatment, the activity of NOS was significantly increased. These results indicated that pretreatment of HUVECs with Gps repressed the decreased production of NO, which was initially caused by a cholesterol insult. However, the mechanisms underlying Gps-increased activity of NOS require further investigation.

The present study used HPLC to analyze which active ingredients may be important in Gps. Gps is identified to be the same as the protopanaxadiol-type ginsenosides $\mathrm{Rd}, \mathrm{Rb}_{1}, \mathrm{Rb}_{3}$, $\mathrm{F}_{2}, \mathrm{Rc}, \mathrm{Rg}_{3}$, malonyl- $\mathrm{Rb}_{1}$ and malonyl-Rd. Ginsenoside $\mathrm{Rb}_{1}$ has been found to have relaxation effects on pulmonary vessels, an effect which can be eliminated by nitro-L-arginine, an inhibitor of NO synthase (21). Furthermore, damage to the cell membrane of myocardiocytes induced by xanthine-xanthine oxidase (X-XO) can lead to a disorder in ion distribution across the membrane and consequently a decrease in the maximal diastolic potential (22). Previous studies indicated that $R b_{1}$, $\mathrm{Rb}_{2}$ and $\mathrm{Rb}_{3}$ attenuated the X-XO-inhibited action potentials and protected the membrane from $\mathrm{X}-\mathrm{XO}$-induced damage through antioxidative action against free radicals $(23,24)$. In the present study, Gps was compared with ginsenosides standard substances $\mathrm{Rb}_{1}$ and $\mathrm{Rb}_{2}$. By HPLC qualitative and quantitative analysis, the contents of Gps were identified as having different compounds, two of which had a similar structure and chemical character to ginsenoside $\mathrm{Rb}_{1}$ and $\mathrm{Rb}_{2}$, which may be responsible for $G p s$-mediated protection.

The present study demonstrated that Gps reduces cholesterol-induced DNA damage via its antioxidative actions and may enhance our understanding of the protective effects of Gps in the circulatory system. 


\section{Acknowledgements}

This study was supported by the Foundation of Science and Technology office of Guizhou Province, China (grant no. 2009-2-178). The authors would like to thank Dr Zhang, Pei-jing and Dr Zhang Feng for their critical discussions and assistance.

\section{References}

1. Piao XL and Wu Q: Progressive studies on Gynostemma pentaphyllum. Lishizhen Medicine and Materia Medica Research 21: 1758-1760, 2010.

2. Liu XY, Wei JM and Zhou R: Study on effective components extraction and antioxidant capacities of Gynostemma pentaphyllum Makino. J Anhui Agri Sci 36: 13670-13672, 2008 (In Chinese).

3. Quan Y and Qian MZ: Effect and mechanism of Gypenosides on the inflammatory molecular expression in high-fat induced atherosclerosis rat. Chinese Journal of Integrated Traditional and Western Medicine 30: 403-406, 2010 (In Chinese).

4. Mercer JR, Cheng KK, Figg N, et al: DNA damage links mitochondrial dysfunction to atherosclerosis and the metabolic syndrome. Circ Res 107: 1021-1031, 2010

5. Botto N, Rizza A, Colombo MG, et al: Evidence for DNA damage in patients with coronary artery disease. Mutat Res 493: 23-30, 2001.

6. Andreassi MG and Botto N: DNA damage as a new emerging risk factor in atherosclerosis. Trends Cardiovasc Med 13: 270-275, 2003.

7. Quan Y and Qian MZ: Cholesterol induces endothelial cells injury by increasing production ofreactive oxygen species and activating NF-kB. Chinese J Pathophysiol 26: 1521-1526, 2010 (In Chinese).

8. Wang HX, Yang YJ and Qian MZ: Cholesterol induces DNA damage in HUVECs. Chinese Journal of Biochemistry and Molecular Biology 28: 442-448, 2012 (In Chinese).

9. Liu F, Ren D, Guo DA, Pan Y, Zhang H and Hu P: Method development for gypenosides fingerprint by high performance liquid chromatography with diode-array detection and the addition of internal standard. Chem Pharm Bull (Tokyo) 56: 389-393, 2008

10. Mahmoudi M, Mercer J, Bennett M: DNA damage and repair in atherosclerosis. Cardiovasc Res 71: 259-268, 2006.
11. Chen X: Cardiovascular protection by ginsenosides and their nitric oxide releasing action. Clin Exp Pharmacol Physiol 23: 728-732, 1996.

12. Thompson JA and Hess ML: The oxygen free radical system: a fundamental mechanism in production of myocardial necrosis. Prog Cardiovasc Dis 28: 449-462, 1986.

13. Jiang Y, Zhong GG, Chen L and Ma XY: Influences of ginsenosides $\mathrm{Rb}_{1}, \mathrm{Rb}_{2}$ and $\mathrm{Rb}_{3}$ on electric and contractile activities of normal and damaged cultured myocardiocytes. Acta Pharmacol Sin 13: 403-406, 1992.

14. Rogakou EP, Pilch DR, Orr AH, Ivanova VS and Bonner WM DNA double-stranded breaks induce histone H2AX phosphorylation on serine 139. J Biol Chem 273: 5858-5868, 1998

15. Ago T, Kitazono T, Ooboshi H, et al: NOX4 as the major catalytic component of anendothelial NAD(P)H oxidase. Circulation 109: 227-233, 2004.

16. Yamagishi $S$, Nakamura $K$, Ueda $S$, Kato $S$ and Imaizumi $T$ : Pigment epithelium-derived factor (PEDF) blocks angiotensin II signaling in endothelial cells via suppression of NADPH oxidase: a novel anti-oxidative mechanism of PEDF. Cell Tissue Res 320: 437-445, 2005.

17. Guzik TJ and Harrison DG: Vascular NADPH oxidases as drug targets for novel antioxidant strategies. Drug Discov Today 11: 524-533 2006.

18. Alderton WK, Cooper CE and Knowles RG: Nitric oxide synthases: structure, function and inhibition. Biochem J 357: 593-615, 2001.

19. Zhou L, Xu YP, Wei Y, et al: Effects of gypenosides on blood lipid and lipid peroxidation in experimental hyperlipidemia rats. Chinese Journal of Applied Physiology 13: 228-232, 2005.

20. Yang YH, Yang J and Jiang QH: Hypolipidemic effect of gypenosides in experimentally induced hypercholesterolemic rats. Lipids Health Dis 12: 154, 2013.

21. Archer SL, Reeve HL, Michelakis E, et al: $\mathrm{O}_{2}$ sensing is preserved in mice lacking the gp91 Phox subunit of NADPH oxidase. Proc Natl Acad Sci USA 96: 7944-7949, 1999.

22. Olszanecki R, Kozlovski VI, Chłopicki S and Gryglewski RJ: Paradoxical augmentation of bradykinin-induced vasodilatation by xanthine/xanthine oxidase-derived free radicals in isolated guinea pig heart. J Physiol Pharmacol 53: 689-699, 2002.

23. Geiszt M, Kopp JB, Várnai P and Leto TL: Identification of Renox, an NAD $(\mathrm{P}) \mathrm{H}$ oxidase in kidney. Proc Natl Acad Sci USA 97: 8010-8014, 2000.

24. Dijkstra G, Moshage H, van Dullemen HM, et al: Expression of nitric oxide synthases, and formation of nitrotyrosine and reactive oxygen species in inflammatory bowel disease. J Pathol 186: 416-421, 1998. 